\title{
Gerakan Sarikat Islam di Bolaang Mongondow Abad ke-20 : Melacak Jaringan Politik dan Pendidikan
}

\author{
Almunauwar Bin Rusli, M.Pd \\ Dosen FTIK IAIN Manado \\ Email : almunauwar.b@yahoo.com
}

\begin{abstract}
Abstrak
Tulisan ini ingin mengkaji tentang gerakan sarikat Islam di Bolaang Mongondow abad ke- 20 yang dilakukan HOS Cokroaminoto yang berfokus pada dua pertanyaan mendasar yaitu bagaimana proses terciptanya jaringan politik dan jaringan pendidikan dalam kurun sejarah. Temuan penting dalam kajian ini adalah (1) Jaringan politik terbentuk karena adanya kesadaran perubahan, kesadaran kolektif, kesadaran sejarah, kesadaran fakta sosial, dan kesadaran objektif (2) Jaringan pendidikan terbentuk karena adanya krisis identitas keislaman, adanya kesamaan visi-misi perjuangan politik Islam dalam melawan kebijakan pemerintah kolonial, dan adanya aktivisme kekeluargaan lintas etnis. Sebagai kesimpulan, umat beragama yang ada di Bolaang Mongondow adalah mayoritas Muslim yang terbentuk atas fase diplomatik, struktural, organisasional dan kultural.
\end{abstract}

Kata Kunci : Gerakan, Sarikat Islam, Bolaang Mongondow

\section{PENDAHULUAN}

\section{Islam dalam Bayang-bayang Kolonial}

Tradisi pendidikan Islam di Jawa sejak abad ke-19 maupun abad ke-20 masih mengalami beberapa problem serius akibat pengaruh pemerintahan kolonial Belanda. Problem ini terbagi menjadi tiga bentuk. Pertama, dimensi kegiatan. Kegiatan pendidikan yang dijalankan Belanda mengandung unsur Kristenisasi, penciptaan masyarakat sipil yang tunduk sepenuhnya kepada pemerintah kolonial, doktrinisasi politik pecah belah, dan adanya diskriminasi pendidikan dengan membedakan antara kaum pribumi dan anak bangsawan (Rachman Assegaf, 2005:14). Kedua, dimensi kelembagaan. Sejak periode VOC pada abad ke-17 dan 
Jurnal Pendidikan Islam Iqra' Vol. 11 Nomor 2 Tahun 2017

Fakultas Tarbiyah dan Ilmu Keguruan [FTIK]

IAIN Manado

ke-18, Gereja Kristen Belanda sudah terlibat dalam penyediaan lembaga pendidikan bagi orang-orang lokal (Inlands Onderwijs). Aktivitas missionaris ini berhasil menambah jumlah pemeluk Kristen di Indonesia Timur. Meskipun pemeluk Kristen hanya berjumlah satu persen dari seluruh populasi pada 1900, di beberapa wilayah seperti Maluku, Sulawesi Utara, Nusa Tengara Timur, Sumatera Utara, sebagian Kalimantan, dan Irian Jaya menurut Gavin Jones jumlah mereka terus mengalami peningkatan meskipun tidak menyebutkan secara eksplisit (Arief Subhan, 2012:103). Ketiga, dimensi pemikiran. Bagi Karel A. Steenbrink, pemikiran pendidikan kolonial Belanda sangat berbeda dengan inti ajaran Islam. Pemikiran peserta didik lebih ditekankan kepada aspek kognitif dan keterampilan duniawi semata. Tidak ada sentuhan spritualitas untuk menghasilkan akhlak alkarimah (Steenbrink, 1994:24).

Kajian ini merupakan sebuah komplementer penting untuk memetakan secara tajam gerakan sarekat Islam di Bolaang Mongondow abad ke-20 kemudian mengeksplorasi peristiwa historis proses terjadinya jaringan politik sekaligus pendidikan antara murid-murid muslim di Bolaang Mongondow dengan kelompok Sarekat Islam di Jawa. Kajian-kajian terdahulu tampaknya belum begitu melebarkan pisau analisis ke daerah yang berada di luar Jawa. Sehingga, memberikan kesan bahwa pengaruh Sarekat Islam seolah tidak begitu besar pada masyarakat muslim di belahan wilayah lain, khususnya Indonesia Timur.

\section{PEMBAHASAN}

Haji Oemar Said (HOS) Cokroaminoto merupakan pimpinan utama Sarekat Islam (SI) 1916, setelah bergabung pada 1912 bersama Haji Samanhoedi dari Solo. Dalam Rapat Akbar Sarekat Islam 1331H/1913 M, beliau membangkitkan kesadaran jiwa umat Islam agar mau berorganisasi untuk menggalang kesatuan dan persatuan. Dari kemauan yang membaja, umat Islam akan memiliki kekuatan. Hanya dengan kekuatan, umat Islam akan memperoleh kemenangan. Melalui kemenangan, umat Islam akan dapat menduduki kekuasaan (Suryanegara, 2009:368). Bernard H.M. Vlekke dalam Nusantara A Histor. of Indonesia menyatakan bahwa Sarekat Islam disambut oleh rakyat sebagai Revival of Islam (Kebangkitan Islam). Bagi mereka, kehadiran Sarekat Islam lebih menarik, merakyat dan tidak eksklusif sebagaimana golongan Boedi Oetomo (Suryanegara,2009:375).Sedangkan, George MC Turnan Kahin dalam Nationalism and Revolution in Indonesia bersepakat bahwa Sarekat Islam adalah gerakan politik pertama yang memprioritaskan hak-hak dasar masyarakat pribumi terutama menyangkut pendidikan serta ekonomi. Hubungan Cokroaminoto dengan Sarekat Islam memang tidak semata bercorak struktural-formal melainkan bercorak fungsional-horizontal. 
Jurnal Pendidikan Islam Iqra' Vol. 11 Nomor 2 Tahun 2017

Fakultas Tarbiyah dan Ilmu Keguruan [FTIK]

IAIN Manado

Corak hubungan fungsional-horizontal antara Cokroaminoto dan Sarekat Islam tentu saja dapat kita dipahami melalui pandangannya terhadap Islam dan Sosialisme. Dia menjelaskan bahwa Islam sangat menjunjung tinggi semangat persaudaraan, kesetaraan dan kebebasan manusia dari segala bentuk tirani. (Tjokroaminoto , 2010). Beliau memiliki perbedaan mendasar dengan aspekaspek tertentu dari Marxisme sebab paham materialismenya harus mengindahkan Tuhan. Dia menegaskan bahwa sosialisme kita ditujukan untuk mencapai keselamatan dunia-akhirat. Hal itu dipertegasnya dalam Tafsir Program-Asas Partai Sarekat Islam Indonesia (1931) yakni "Dalam Negara Indonesia yang merdeka, maka tujuan perjuangan PSII harus berwatak demokratis sebagaimana QS Asy-Syura : 38" (Yudi Latif,2011:407). Meminjam istilahnya Bassam Tibi, maka tampaknya HOS Cokroaminoto tidak hanya menjadikan Islam sebagai seperangkat norma kehidupan atau rumusan keimanan kepada Tuhan secara privat, melainkan mengusung iklim "Islamisme" secara terorganisir sekaligus terkontrol dengan rapi. Islamisme berarti Islam yang dijadikan ideologi pergerakan (politik) untuk meraih perubahan signifikan.

\section{Jaringan Politik dalam Spirit Islam Pribumi}

Setelah berbicara sedikit tentang sosok HOS Cokroaminoto dan Sarekat Islam, tentu membuat kita ingin mengetahui apa sebetulnya strategi khusus yang dimainkan oleh beliau dalam mensukseskan ideologi Islam dan sosialismenya kepada masyarakat pribumi kelas menengah bawah yang kurang mendapat perhatian penuh dari pemerintah kolonial Belanda saat itu. Modifikasi sistem pendidikan merupakan senjata pamungkas Tuan Cokro agar masyarakat mendapatkan pengetahuan, keterampilan juga keberanian dalam menyampaikan hak-hak politik, agama, juga ekonomi mereka kepada pemerintah kolonial Belanda. Tiga faktor utama sebagaimana yang telah saya paparkan dalam pendahuluan kajian ini juga ikut memprovokasi umat Islam untuk bangkit dari penjajahan secara intelektual, struktural maupun kultural. Oleh sebab itu, bagian ini akan mencoba memaparkan gerakan progresif apa saja yang sudah dilakukan oleh Tuan Cokro di Jawa agar masa depan Pendidikan Islam (dalam arti luas) sebagai alat perjuangan tetap terjaga dan gempuran penjajah.

Adapun gagasan beserta gerakan progresif yang dimaksud meliputi enam bidang. Pertama, hapus kerja paksa. Kedua, hapus diskriminasi penerimaan murid di sekolah. Ketiga, wajib belajar hingga 15 tahun. Keempat, beasiswa ke luar negeri. Kelima, pembentukan dewan daerah. Keenam, pengakuan hari-hari besar Islam. Dalam Program Asas dan Program Tadhim, HOS Cokroaminoto menyatakan bahwa pengajaran dan pendidikan adalah "Kekuatan tenaga untuk mendirikan sekolahnya sendiri yang cukup luas pengajarannya dalam ilmu dunia 
Jurnal Pendidikan Islam Iqra' Vol. 11 Nomor 2 Tahun 2017

Fakultas Tarbiyah dan Ilmu Keguruan [FTIK]

IAIN Manado

dan ilmu agama. Selalu mementingkan perasaan kebangsaan, terlebih lagi mencintai Negeri tumpah-darah dan mengadakan berbagai macam organisasi guna memberi pendidikan berdasarkan Islam kepada anak-anak serta pemuda, baik di dalam sekolah maupun di luar sekolah".

Selain itu, HOS Cokroaminoto juga berpandangan bahwa sekolah hendaklah menjadi percampuran agama dan ilmu pengetahuan modern. Sedangkan, agar gerakan pengajaran Al-Qur'an dapat berjalan dengan baik maka perlu diikuti beberapa fase tertentu. Langkah pertama (Lager Onderwijs), yakni: pengajaran yang ditempuh dalam jangka waktu 5, 6 atau 7 tahun. Langkah kedua (Middelbaar Onderwijs), yakni: pengajaran yang ditempuh dalam waktu 4 atau 5 tahun. Langkah universiteit (Hooger Onderwijs), yakni: pengajaran pagi para pemuda yang kurang lebih usia 20 atau 21 tahun. Berdasarkan data sejarah ini, maka semakin jelas pula bahwa memang ada perbedaan fundamental terkait identitas, tradisi maupun arah transformasi antara lembaga pendidikan Belanda dan lembaga pendidikan Islam. Sekolah Belanda tidak pernah mengajarkan Quran dan Hadits, karena bagi penulis keduanya memiliki pertimbangan serius.

Kedua kitab itu kadang-kadang sering menimbulkan semangat pan-Islamisme yang ditandai dengan berangkatnya masyarakat muslim pribumi ke Tanah Suci. Snouck Hurgronje pun sudah mengingatkan bahwa gerakan itu harus diwaspadai. Mungkin juga lahirnya kebijakan Ordonansi Guru tahun 1905 juga terinspirasi dari saran Snouck. Akhirnya pendidikan Islam kala itu semakin terjepit. Hasil kajian Deliar Noer menunjukkan, Tjokroaminoto berhasil mengubah haluan SI dari penciptaan kemajuan bagi rakyat Hindia Belanda menjadi perjuangan untuk pemerintahan sendiri. Rakyat Indonesia harus diberi hak menyuarakan aspirasi dalam persoalan-persoalan politik (Jajat Burhanudin, 2012:238-239).

\section{Jaringan Pendidikan Muslim Jawa dan Bolaang Mongondow}

Setelah membahas inti variasi gerakan pendidikan Islam yang dilakukan oleh HOS Cokroaminoto di Jawa pada abad ke-20, maka pada bagian ini saya akan menarik fenomena tersebut ke dalam konteks lokalitas di Bolaang Mongondow. Harus diakui bahwa prinsip hidup Cokroaminoto yang menggabungkan antara spirit Islam dan sosialisme (setinggi-tinggi ilmu, semurni-murni tauhid, sepintarpintar siasat) telah mampu menyentuh jantung hati, menginspirasi kemudian menciptakan jaringan keilmuan dengan murid-murid muslim di tanah Bolaang Mongondow, khususnya daerah Kotamobagu.

Kotamobagu adalah salah satu kota kecil yang merupakan bagian dari Sulawesi Utara. Jarak tempuh dari Manado sekitar 5 jam. Islam menempati posisi 
mayoritas di sini. Meski demikian, tradisi awal pendidikan Islam di Bolaang Mongondow dapat dikatakan cukup tertinggal dibandingkan dengan tradisi pendidikan Kristen dari Minahasa yang disponsori Zending. Di sinilah, muncul keprihatinan batin beberapa murid-murid muslim lalu memilih membangun jaringan keilmuan dengan para guru-guru Sarekat Islam. Jika ditinjau dari konteks historisitas, lembaga pendidikan di Bolaang Mongondow yang mempunyai izin dari Gubernumen hanyalah Missie Zending dan telah membuka sekolahnya sekitar tahun 1830 di Desa Bolaang pada masa kekuasaan Raja Bolaang Mongondow Paduka Tuan Jacobus Manoppo. Namun,segera ditutup karena guru Bastian meninggal dunia dan juga belum ada bantuan dari Pemerintah Belanda.

Sekolah di Bolaang Mongondow nanti efektif setelah Belanda berkuasa dan menerima siswa pada tahun pelajaran 1904-1905 di bawah Missie Zending pimpinan pendeta Dunnebier yang pembinanya adalah Nederlandch Zending Genootschap (N.Z.P) dengan guru-guru dari Minahasa.Kemudian, sekolah tersebut berkembang dan pada tahun 1911 berdirilah Holandsch Inlandche School (HIS) Zending yang berada di Kotamobagu dan pada awalnya penerimaan siswa baru hanya untuk anak-anak bangsawan sehingga mendapat protes dari masyarakat pribumi. Maka, pada tahun 1916 Raja Bolaang Mongondow merubah sistem penerimaan siswa baru secara umum (Z.A. Lantong, 1995:37).

Perkembangan pendidikan di Bolaang Mongondow yang dilaksanakan oleh Missie Zending cukup membawa rakyat ke dalam kehidupan intelektual berpikir secara kritis yang sangat mempengaruhi kemajuan dunia pendidikan pada masa berikutnya, serta sangat menyumbang tumbuhnya pergerakan Sarekat Islam dengan sikap kerasnya yang non kooperatif terhadap pemerintah Belanda. Patut diperhatikan bahwa memang benar bahwa ekspansi sekolah Kristen Protestan dari Minahasa ke Bolaang Mongondow sangatlah besar dan itu membuktikan pengamatan Gavin Jones sebelumnya. Pada tahun 1920 melalui Makmur Lubis yang diutus Pimpinan Sarekat Islam (SI) H.O.S. Cokroaminoto datang ke Bolaang Mongondow untuk membuka cabangnya yang berpusat di Desa Molinow. Masuknya SI di Bolaang Mongondow disamping menumbuhkan rasa kebangsaan dan ke-Islaman di kalangan masyarakat Bolaang Mongondow yang mayoritas beragama Islam dan meringkuk di bawah tekanan pemerintah Belanda. Kedatangan SI dimanfaatkan oleh tokoh-tokoh Islam waktu itu untuk mengimbangi pengaruh pendidikan zending yang mereka anggap dapat melemahkan syiar Islam yang sudah dianut mayoritas penduduk Bolaang Mongondow. Maka, munculah pimpinan SI yang merupakan seorang putra daerah asli kelahiran Desa Molinow, yakni Adampe Dolot (Z.A. Lantong, 1995:38). 
Jurnal Pendidikan Islam Iqra' Vol. 11 Nomor 2 Tahun 2017

Fakultas Tarbiyah dan Ilmu Keguruan [FTIK]

IAIN Manado

Adampe Dolot kemudian segera mengajukan permohonan kepada Controleur di Kotamobagu dan residen di Manado untuk membuka sekolah seperti yang dikerjakan zending. Tapi, mereka menolak dengan alasan bahwa izin semacam telah diberikan kepada zending. Dari respons atas kebijakan pemerintah kolonial ini jelas memperlihatkan adanya pertentangan dengan politik etika di bidang pendidikan rakyat yang sangat menghendaki dilaksanakannya tradisi pendidikan yang merata bagi rakyat di Sulawesi Utara. Pada tahun 1925, Adampe Dolot pun berangkat ke Jakarta dengan bantuan penuh A.P. Mokoginta (ayah kandung Letjen (Pur) A.J. Mokoginta yang telah lebih dahulu disingkirkan Belanda, karena dicurigai menanamkan jiwa kebangsaan di Bolaang Mongondow untuk menuju Indonesia merdeka). Dengan dukungan A.P. Mokoginta, Adampe Dolot langsung menghadap dan mengajukan permohonan kepada Departement Van Onderwijs en Eeredienst. Akhirnya permohonan mereka dikabulkan untuk membuka sekolah-sekolah Islam di Bolaang Mongondow (Laporan penelitian Depdikbud, 1978:39-86).

Maka, sejak tahun 1926, di Bolaang Mongondow terdapat dua organisasi keagamaan yang mengelola persekolahan, yaitu: zending dan PSII. Sementara itu, pengaruh Sarekat Islam makin meluas di seluruh kerajaan Bolaang Mongondow. Walaupun untuk masuk menjadi anggota SI harus melalui bai'at, namun anggotaanggota PSII terus bertambah di bawah kepemimpinan Adampe Dolot. Antara tanggal 17-24 Agustus 1933, PSII mengadakan kongres di Bolaang Mongondow (sebelumnya pada tahun 1923 kongres SI se-Sulawesi diadakan di Manado) yang dihadiri oleh HOS Cokroaminoto, Akis dan A.M. Sangadji. Dari Manado oleh Makmur Lubis, O.N. Pakaja dan Jakin Intan Permata. Sedangkan dari Bolaang Mongondow sendiri dihadiri oleh Adampe Dolot, Johan Damopolii, Zakaria Imban, Husen Raupu, Frans T. Manoppo dan Hadji Saleh Mustafa. Kongres ini mengeluarkan program dalam bidang perekonomian, intensifikasi pertanian dan pembentukan koperasi (Laporan penelitian Depdikbud, 1978:147).

Maka didirikanlah gedung-gedung sekolah dan balai pertemuan umum. Sedangkan, di tiap desa didirikan semacam koperasi yang bernama Hajanatullah. Koperasi yang berpusat di Desa Molinow ini dipimpin oleh Hadji Djihamid dan Salam Detu. kemudian mencerminkan sikap kemandirian umat Islam di Bolaang Mongondow sebagaimana inti pemikiran HOS Cokroaminoto sebelumnya. Karena keuangan PSII semakin kuat, maka pimpinan pusat PSII mengabulkan permohonan pimpinan cabang PSII Bolaang Mongondow untuk mengirim beberapa orang guru dari Jawa, antara lain: Mohammad Syafi'I Wirakusuma, Mohammad Djajuli Kartawinata, Rachmad Hardjodiwirjo, Soekirman, Soemardjo Soerdjopranoto di tambah Ali Bahmid dari Manado, Oesman Hadjoe dari Gorontalo dan Mohammad Tahir dari Sangir Talaud. 
Jurnal Pendidikan Islam Iqra' Vol. 11 Nomor 2 Tahun 2017

Fakultas Tarbiyah dan Ilmu Keguruan [FTIK]

IAIN Manado

Dengan datangnya guru-guru tersebut, maka didirikanlah beberapa sekolah asuhan PSII yang bernama B.P.P.I (Balai Pendidikan dan Pengajaran Islam) sebagai upaya mengimbangi pengaruh pendidikan zending yang semakin meluas di Bolaang Mongondow. Pada tahun 1927, untuk memenuhi guru di BPPI Molinow Kotamobagu, diadakanlah pelatihan guru selama 6 bulan yang diambil dari lulusan zending di Kotamobagu serta lulusan dari Gorontalo dengan nama C.V.O (Cursus Voor Volks Onderwijzer) dan Kweekeling. Selain itu, SI Kotamobagu mengirim murid-murid muslim Bolaang Mongondow, yakni Haruna Pundong, Zakaria Imban dan Yahya Mokobombang ke perguruan kweekschool Adhi Dharmo . Pada tahun 1931, didirikanlah sekolah Holland Inlandsch School (HIS BPPI 7 Tahun) sebagai kelanjutan dari sekolah rakyat 2 tahun. Hubungannya dengan sekolah Islam ialah karena guru-guru yang mengajar di dalamnya adalah putra-putra asli Bolaang Mongondow lulusan perguruan Adhi Dharmo. Zakaria Imban, misalnya.

Saya berpendapat bahwa sengaja BPPI mengadakan kerja sama dalam bidang pendidikan dengan pemerintah Belanda agar supaya suasana pada saat itu tidak memanas, karena warganya bisa duduk bersama-sama dalam mengenyam pengetahuan dan pemikiran yang moderat dan bersahaja. Untuk memenuhi guruguru, didatangkan dari pulau Jawa termasuk para alumni dari perguruan Adhi Dharmo, yaitu Ramelan Djojo Adiguno, Zakaria Imban, Moh. Safei Wirakusuma, Ahmad Harjodiwirjo, Sumaryo, Ahmad S. Bahalwan, Saldan Martasiswojo, Masud Admodiwirjo, Soekirman, Harsono Cokroaminoto, Zazuli Kartawinata, Akis, Sukardi Siswa Pranoto, Subari Moh. Muljo, Masngud Atmodiwirja, Moh. Hamdi, Sarwoko, dan Sukardi.

Kurikulum sekolah tersebut seimbang antara pendidikan agama Islam dan pengetahuan umum, yaitu 45\%:55\%, serta menggunakan bahasa pengantar bahasa Indonesia, Belanda, dan Bahasa Arab. Pada tahun 1937 di dirikan Kweek School atau sekolah persamaan guru 4 tahun sebagai kelanjutan dari HIS tersebut di atas. Pada tahun 1950 sampai dengan 1952 Kweek School PSII dirubah menjadi Balai Pendidikan Umum (BPU) tingkat SLTP, kemudian pada tahun 1953 sampai dengan tahun 1955 diubah menjadi Sekolah Menengah Islam (SMI) setingkat SLTP, kemudian di tahun 1956 diubah menjadi SMP Cokroaminoto, sedangkan gedung yang digunakan adalah gedung SMP Cokroaminoto, sekarang ini terletak di Jalan Adampe Dolot. Selain itu, maka atas permintaan masyarakat desa Bongkudai, dibukalah SMP Cokroaminoto Bongkudai pada tahun 1960. Pada tahun 1965 telah diterbitkan Surat Keputusan Menteri Pendidikan Dasar dan Kebudayaan RI No. 45/S/Um. Manado tertanggal 19 Februari 1965 yang ditandatangani Kepada Perwakilan Departemen PD dan K daerah Sulawesi Utara Tengah a.n. R.E. Kalempou tentang SMP Cokroaminoto Molinow dengan status 
Jurnal Pendidikan Islam Iqra' Vol. 11 Nomor 2 Tahun 2017

Fakultas Tarbiyah dan Ilmu Keguruan [FTIK]

IAIN Manado

bersubsidi. Untuk angkatan pertamanya, sekolah ini menerima siswa sebanyak 25 orang dan menggunakan guru-guru dari HIS BPPI tamatan Adhi Dharmo dengan tujuan agar seluruh desa di Kabupaten Bolaang Mongondow dapat didirikan HIS, serta menggunakan gedung yang terletak di Jalan Veteran No. 1 Kotamobagu Barat yang saat ini dijadikan Kantor Sarekat Islam Kota Kotamobagu dan Kantor Yayasan Pendidikan Cokroaminoto Kabupaten Bolaang Mongondow. Pada tahun 1939, hasil dari pendidikan persamaan guru tersebut di kirim ke seluruh pelosok desa-desa di Bolaang Mongondow dan dengan di dukung oleh anggota Kaum Sarekat Islam di desa yang bersangkutan didirikan sekolah di bawah asuhan BPPI. Desa-desa itu adalah :

Wilayah Kota Kotamobagu: Desa Molinow, Desa Motoboi Kecil, Desa Poyowa Besar, Desa Moyag, Desa Gogagoman, Desa Bakan. Wilayah Kab. Bolaang Mongondow : Desa Tanoyan, Desa Tabang, Desa Ikhwan, Desa Wangga, Desa Otam, Desa Bilalang, Desa Poigar, Desa Nonapan, Desa Bolaang, Desa Komangaan, Desa Solog, Desa Bumbung.Wilayah Bolaang Mongondow Timur : Desa Bongkudai, Desa Molobog, Desa Matabulu, Desa Nuangan, Desa Tutuyan, Desa Kotabunan, Desa Tombolikat, Desa Motongkad. Wilayah Bolaang Mongondow Selatan : Desa Toluwaya, Desa Bakida, Desa Salongo, Desa Lion, Desa Tolondadu, Desa Pinolosian, Desa Mataindo, Desa Motandoi. Wilayah Minahasa Tenggara : Desa Ratatotok.

Semua sekolah yang disebutkan di atas saat ini telah mengalami perubahan orientasi pendidikannya. Karena faktor hegemoni politik (kepentingan pemerintah daerah) yang berkuasa pada waktu itu. Atau bisa dikatakan model pendidikannya tidak lagi seperti BPPI yang sangat khas dengan nuansa keagamaan. Adapun pembiayaan sekolah baik tingkat SD maupun SMP dibiayai oleh swadaya masyarakat setempat, yaitu dari kaum Syarikat Islam atau PSII yang disertai pemberian wakaf-wakaf dari anggota PSII dan hampir semua alumni/lulusan dari C.V.O, Kweekeling, Kweekschool yang disebarluaskan di desa-desa telah diangkat menjadi guru pegawai negeri. Sekolah-sekolah tersebut berlangsung sampai pada tahun 1946 kemudian disesuaikan dengan nama Sekolah Rakyat Badan Pendidikan dan Pengajaran Islamiyah Cokroaminoto, kemudian berubah menjadi Sekolah Dasar BPPI Cokroaminoto.

Dengan adanya peraturan Menteri Pendidikan, maka diadakan penyesuaian lagi pengelolaan sekolah, yaitu harus mempunyai badan hukum. Maka Dewan Pimpinan Wilayah Sarekat Islam Provinsi Sulawesi Utara mendirikan Badan Hukum dengan nama Yayasan Pendidikan Islam Cokroaminoto yang berkedudukan di Manado. Seiring dengan perkembangan otonomi daerah, maka untuk mempercepat pelayanan terhadap sekolah-sekolah dasar didirikanlah 
Jurnal Pendidikan Islam Iqra' Vol. 11 Nomor 2 Tahun 2017

Fakultas Tarbiyah dan Ilmu Keguruan [FTIK]

IAIN Manado

Yayasan Pendidikan Islam Cokroaminoto Kabupaten Bolaang Mongondow dengan Akta No. 28 tanggal 18 Mei 1989 oleh notaris Urip Manoppo SH. Pada zaman pemerintahan Orde Baru, banyak SD Cokroaminoto di desa-desa dijadikan SD Negeri karena dianggap bahwa Yayasan Pendidikan Cokroaminoto berafiliasi pada PSII dan sesudah fusi partai itu, PSII bergabung menjadi Partai Persatuan Pembangunan (PPP). Selain itu pula telah didirikan SD INPRES di tiap desa dan untuk itu saat ini sekolah-sekolah yang dikelola oleh Yayasan Pendidikan Cokroaminoto Kabupaten Bolaang Mongondow adalah sebagai berikut :

Tingkat Sekolah Dasar/Ibtidaiyah : SD Cokroaminoto Molinow, SD Cokroaminoto Poyowa Besar, SD Cokroaminoto Bakan, SD Cokroaminoto Wangga, SD Cokroaminoto Ikhwan, SD Cokroaminoto Poigar, SD Cokroaminoto Solog, SD Cokroaminoto Bumbung, SD Cokroaminoto Tutuyan, SD Cokroaminoto Motongkad, SD Cokroaminoto Toluwaya, SD Cokroaminoto Pangiya. Tingkat Sekolah Lanjutan Pertama/Tsanawiyah : SMP Cokroaminoto Kotamobagu, SMP Cokroaminoto Solog, SMP Cokroaminoto Salongo. Tingkat Sekolah Menengah Lanjutan Atas/Madrasah Aliyah : SMK Cokroaminoto Kotamobagu (saat ini telah dikukuhkan menjadi SMK Rintisan Bertaraf Internasional), SMK Cokroaminoto Bolaang Uki di Salongo. Mencermati perkembangan Lembaga Pendidikan Islam di Bolaang Mongondow pada awalawal abad ke-20 di atas memang memberikan sebuah kesadaran sejarah, bahwa HOS Cokroaminoto menjadikan sekolah sebagai basis aspirasi agama, politik dan ekonomi kaum pribumi. Sekali lagi, sejarawan Bonnie Triyana menilai salah satu keunggulan Cokroaminoto adalah sikapnya yang egaliter. Tidak memandang usia, status, atau jabatan. Penting diketahui juga, Hingga 17 Desember 1934, Harsono (anaknya Tuan Cokro) masih berada di Bolaang Mongondow, Sulawesi Utara untuk bertugas menjadi propagandis partai di sana (Mulawarman, 2015:202). Untuk lebih jelasnya simak penuturan langsung dari beliau di bawah ini :

“... Pada sekitar tahun 1932-1934 saya ditugaskan oleh Pucuk Pimpinan PSII semula untuk mengadakan propaganda dalam rangka menyebarluaskan asas perjuangan partai di Bolaang Mongondow. Tetapi kemudian karena dianggap perlu berhubung dengan keadaan rakyat Minahasa pada umumnya dan khususnya rakyat di daerah Bolaang Mongondow masih jauh tertinggal dipandang perlu untuk ditingkatkan kecerdasannya. Maka saya selama lebih dari dua tahun menetap di sana dan mendapat tugas pula sebagai seorang guru sekolah. Pada waktu itu, daerah Bolaang Mongondow termasuk salah satu basis dari PSII. Seperti di daerah-daerah lainnya, maka daerah ini juga mendapat perhatian dari Pucuk Pimpinan PSII terutama yang menyangkut segi pendidikan untuk rakyat. Di daerah ini, PSII banyak mendirikan perguruan-perguruan, mulai dari yang terendah sampai ke tingkat sekolah menengah, khususnya Kweek School yang pada waktu itu memang sangat banyak dirasakan akan kebutuhan tenaga-tenaga guru. Saya mendapat porsi mengajar Bahasa Inggris oleh karena 
Jurnal Pendidikan Islam Iqra' Vol. 11 Nomor 2 Tahun 2017

Fakultas Tarbiyah dan Ilmu Keguruan [FTIK]

IAIN Manado

saya pernah belajar di Hindustan. Usia saya pun masih sangat muda pada waktu itu Di Bolaang Mongondow, saya tinggal di Desa Molinow bersama Bapak Adampe Dolot, Ketua Umum PSII Cabang Bolaang Mongondow. Beliau wafat di penjara Sukamiskin, Bandung. Berdasarkan keputusan pengadilan beliau di vonis 4 tahun dan harus menjalani hukumannya di Jawa.."(Harsono, 1983:47-48)

Jika kita berkunjung ke Bolaang Mongondow saat ini maka akan mendapati banyak sekali SD/SMP/SMK Cokroaminoto di sana. Sebuah peninggalan yang sangat berharga, sedangkan di Minahasa nyaris tidak banyak terdapat Yayasan Cokroaminoto akibat kebijakan politik kolonial masa lalu. Fenomena itu bisa kita pahami ketika pada tahun 1918 Abraham Patra Mokoginta dipanggil lalu diperingatkan oleh Gubernur Jenderal de Graaf van Limburg Stirum mengenai masalah politik. Karena pada tahun tersebut Partai Sarekat Islam Indonesia mulai datang ke Sulawesi Utara untuk menyebarkan paham organisasinya. Di Manado, mereka memang jelas tidak diizinkan untuk menyebarkan paham Islam dan sosialismenya. Namun, di Bolaang Mongondow mereka sangat diakomodasi oleh Abraham Patra Mokoginta. Abraham memang bukan bergaya Islam fanatik, tapi atas pertimbangan komposisi umat Islam di Bolaang Mongondow yang besar, dia lantas memberikan ruang bagi PSII untuk melakukan gerakan-gerakan sosial yang berpijak pada prinsip sosialisme-humanistik.

Sam Ratulangi pernah menulis "Maar toch moet men een grote factor niet verwaarlozen $n l$ : debewustwording van de inlandsche maatshappij, en zien wij tevens in de Sarikat Islam een krachtige nationale actie : het is de uiting van een volk dat, in zeker stadium gekomen, gehoord wil worden als er over hem beslist wordt" (Bert Adrian Supit,2014:52-53). Sam Ratulangi sebagai pribumi Minahasa memiliki pemikiran bahwa Sarekat Islam adalah salah satu dari sebuah organisasi keagamaan sehingga akan terjadi pertemuan propaganda agama dan kontra propaganda agama yang lain. Baik Kristen maupun Islam, keduanya adalah agama bertipe misionaris. Sam Ratulangi juga mengakui bahwa dalam kehidupan umat Islam tidak ada pemisahan antara agama dan politik, "Geen scheiding van godsdienst en politik".

Meminjam kerangka teori yang dikembangkan oleh Sidney Tarrow, maka gerakan Partai Sarekat Islam Indonesia (PSII) cukup berhasil karena mereka mampu menciptakan tiga model gerakan. Pertama, membuka peluang politik (political opportunity) bagi masyarakat akar rumput yang merasa kekurangan akses terhadap lembaga-lembaga, yang bertindak atas nama tuntutan-tuntutan baru atau menentang kebijakan penguasa kolonial (contentious politics). Muslim Bolaang Mongondow yang tergabung dalam Sarekat Islam bergerak berdasarkan tujuan bersama atas spirit solidaritas sosial, bukan sebagai ekspresi ekstrimitas, kekerasan dan kekecewaan. Sekali lagi, aksi mereka rasional, berorientasi dan 
Jurnal Pendidikan Islam Iqra' Vol. 11 Nomor 2 Tahun 2017

Fakultas Tarbiyah dan Ilmu Keguruan [FTIK]

IAIN Manado

terorganisasi secara rapi. Bagi Noorhadi Hasan, ketika aksi mereka didasari jaringan-jaringan sosial dan struktur koneksi yang padat serta bersandar pada kerangka-kerangka konsensual dan kultural, maka mereka dapat mengembangkan dan mempertahankan gerakan itu ketika berhadapan dengan lawan (Noorhaidi Hasan, 2012:129).

Kedua, keberadaan PSII di Bolaang Mongondow memliki kemampuan terkait seni mengkomunikasikan pesan untuk membujuk massa dan meraih dukungan sekaligus partisipasi mereka. Mereka hebat dalam melakukan pembingkaian (framing) isu, simbol agama dan dikontekstualisasikan dengan realitas kebutuhan pribumi. Framing ini kemudian perlahan tapi pasti mulai memunculkan identitas mereka yang bercita rasa kolektif. Rasa identitas kolektif dalam spirit regionalisme, nasionalisme dan keislaman yang kuat inilah yang ikut menentukan keputusan yang diambil oleh kelompok Muslim Bolaang Mongondow lalu disesuaikan dengan kegiatan-kegiatan sosial-keagamaan maupun politikpendidikan di sana. Namun, surat kabar lokal di Bolaang Mongondow pada awal abad ke-20 yang membantu menyebarkan pesan-pesan gerakan sosial ini belum begitu jelas.

Ketiga, selain berhasil membuka peluang politik dan pembingkaian (framing), PSII juga tekun dalam proses mobilisasi massa (mobilizing structure) secara menyilang antar kepala daerah di Bolaang Mongondow. Dalam jaringan mobilisasi massa secara menyilang inilah seseorang dapat berinteraksi, saling mempengaruhi satu sama lain, bernegosiasi dan dengan itu menetapkan kerangka kerja konseptual dan motivasional untuk melaksanakan aksi. Jaringan mobilisasi massa yang dilakukan PSII di Bolaang Mongondow secara umum bersifat formal. Jaringan ini dipandang sebagai instrumen efektif untuk pemberdayaan kolektivitas-kolektivitas yang secara politis tersingkir. Oleh sebab itu, sekolah dibangun, organisasi dikembangkan dan koperasi difungsikan.

\section{PENUTUP}

Pertama,mengenai gerakan pendidikan Islam yang dimotori oleh HOS Cokroaminoto setidaknya dapat dipahami melalui fenomena bangkitnya kesadaran pribumi. Kesadaran ini meliputi kesadaran perubahan, kesadaran kolektif, kesadaran sejarah, kesadaran fakta sosial, dan kesadaran objektif. Akumulasi kesadaran inilah yang memicu sekaligus memacu pergerakan untuk melawan Belanda.Tjokroaminoto memiliki pendidikan Barat sehingga ia mampu menyesuaikan gerakan perlawanan. Menurut Shiraishi, Islam untuk Tjokroaminoto "tidak lebih dan tidak kurang sebagai identitas dasar bangsa" 
Jurnal Pendidikan Islam Iqra' Vol. 11 Nomor 2 Tahun 2017

Fakultas Tarbiyah dan Ilmu Keguruan [FTIK]

IAIN Manado

(Laffan, 2003:167-168). Kedua, mengenai masalah terjalinnya jaringan politik dan pendidikan dapat dipahamimelalui tiga kerangka berpikir yakni (a) muncul krisis identitas keislaman, (b) adanya kesamaan visi-misi perjuangan politik Islam dalam melawan kebijakan pemerintah kolonial, (c) adanya aktivisme kekeluargaan lintas etnis. Terlepas dari itu, sepertinya organisasi-organisasi tarekat tidak terdengar sama sekali dalam jaringan keilmuan ini. Misalnya perkembangan neo-sufisme. Fazlur Rahman sudah menjelaskan bahwa sebetulnya neo-sufisme adalah tasawuf yang telah diperbarui dari orientasi ecstatic dan metafisiknya lalu digantikan dengan dalil-dalil ortodoksi Islam. Neo-sufisme menekankan dan memperbaharui faktor-faktor moral asli dan kontrol diri yang puritan dalam tasawuf dengan melenyapkan praktik tasawuf populer yang menyimpang. Penting dicatat bahwa pusat perhatian neo-sufisme adalah rekonstruksi sosio-moral dari masyarakat muslim. Karena keringnya cairan yang dipancarkan oleh gerakan tarekat bergaya neo-sufisme masa lampau, maka makna jaringan keilmuan di atas menurut pengamatan saya tidak begitu kuat lagi untuk masa sekarang.

Jaringan pendidikan ini terfokus pada upaya merekonstruksi kembali pondasi epistem umat Islam di Bolaang Mongondow. Rekonstruksi epistem tersebut meliputi (a) sumber pendidikan Islam harus berbasis nilai profetik (humanisasiliberasi-transendensi) sebagaimana makna dari QS Ali Imran :110 (b) metode pengajaran pendidikan Islam harus berbasis paedagogik transformatif (c) kriteria pendidikan Islam harus berbasis sosialisme-humanistik. Upaya-upaya konkret dalam merekonstruksi kembali epistem keilmuan pendidikan Islam di Bolaang Mongondow mesti berfokus pada person, knowledge dan institusion. Memang tidak bisa di pungkiri bahwa umat beragama yang ada di Bolaang Mongondow adalah mayoritas Muslim yang terbentuk atas fase diplomatik, struktural, organisasional dan kultural. Berbeda dengan daerah Minahasa yang mayoritas beragama Kristen Protestan. Identitas keislaman di daerah ini tidak terlepas juga dari peran $D a{ }^{\prime} i$ atau Ustadz yang aktif berdakwah berdasarkan ideologi Ahlusunnah wal Jamaah. 
Jurnal Pendidikan Islam Iqra' Vol. 11 Nomor 2 Tahun 2017

Fakultas Tarbiyah dan Ilmu Keguruan [FTIK]

IAIN Manado

\section{Bibliografi}

Assegaf, Abd. Rachman. 2005. Politik Pendidikan Nasional : Pergeseran Kebijakan Pendidikan Agama Islam dari Praproklamasi ke Reformasi, Jakarta : Kurnia Kalam Press.

Burhanudin, Jajat. 2012. Ulama \& Kekuasaan : Pergumulan Elite Muslim dalam Sejarah Indonesia, Bandung : Mizan.

Hasan, Noorhaidi. 2012. Islam Politik di Dunia Kontemporer : Konsep, Genealogi, Teori, Yogyakarta : Suka Press.

Laffan, Michael Francis. 2003. Islamic Nationhood and Colonial Indonesia : The Umma Below the Winds, London \& New York : Routledge.

Lantong, Z.A. 1995. Sejarah Islam di Bolaang Mongondow, Kotamobagu : Yayasan Cipta Karya Nusa.

Laporan hasil penelitian, 1978. Sejarah Kebangkitan Nasional Daerah Sulawesi Utara, Jakarta : Departemen Pendidikan dan Kebudayaan.

Latif, Yudi. 2011. Negara Paripurna : Historisitas, Rasionalitas, dan Aktualitas Pancasila, Jakarta: Gramedia Pustaka Utama.

Mulawarman, Aji Dedi. 2015. Jang Oetama : Jejak dan Perjuangan HOS Tjokroaminoto, Yogyakarta: Galang Pustaka.

Steenbrink, Karel A. 1994. Pesantren, Madrasah, Sekolah : Pendidikan Islam dalam Kurun Modern Jakarta : LP3ES.

Steenbrink, Karel A. 2005. Orang-orang Katolik di Indonesia 1808-1942, Maumere : Ledalero.

Subhan, Arief. 2012. Lembaga Pendidikan Islam Indonesia Abad ke-20 : Pergumulan antara Modernisasi dan Identitas, Jakarta : Kencana.

Supit, Bert Adriaan. 2014. Ratulangi \& Wenas Inspirasi Minahasa, Jakarta : Bina Insani.

Suryanegara, Ahmad Mansur. 2009. Api Sejarah : Mahakarya Perjuangan Ulama dan Santri dalam Menegakkan NKRI, Bandung : Salamadani Press.

Tjokroaminoto, HOS. 2010. Islam dan Sosialisme, Bandung : Sega Arsy.

Tjokroaminoto, Harsono. 1983. Menelusuri Jejak Ayahku, (Jakarta : Arsip Nasional Republik Indonesia. 